\section{EL SENTIR FRENTE A LA ESTIGMATIZACIÓN TERRITORIAL. TRAVESÍAS DE TOPOFILIA EN EL SUR DE QUITO'}

\author{
Alfredo Miguel Santillán Cornejo ${ }^{2}$
}

\section{Resumen}

Quito, la capital ecuatoriana, se caracteriza por un orden urbano con un fuerte componente fantasioso, en el que el denominado 'Sur' es imaginado como un espacio subalterno en relación al 'Norte', generando efectos estigmatizantes. El artículo se centra en mostrar las emociones y sentimientos que devienen de una situación de segregación con un fuerte componente imaginario, partiendo de que la condición ficcional no deja de tener repercusiones concretas en la construcción de sentido de apego, pertenencia y arraigo hacia el espacio habitado. Estas tensiones se pueden sintetizar en dos frentes: por un lado las emociones de malestar e ira frente a la humillación que se capitalizan en disputas

\section{FEELINGS IN THE FACE OF TERRITORIAL STIGMATIZATION. TOPOPHILIA TRAJECTORIES IN SOUTH QUITO'}

\author{
Alfredo Miguel Santillán Cornejo²
}

\section{Abstract}

Quito, the capital of Ecuador, is characterized by an urban order with a strong fantasy component in which the so-called 'South' is imagined as a subaltern space in relation to the 'North', generating stigmatizing effects. Based on the fact that the fictional condition has concrete repercussions in the construction of a sense of bonding, belonging and attachment to the inhabited space, this paper focuses on showing the emotions and feelings resulting from $a$ situation of segregation with an important imaginary component. These tensions can be synthesized in two aspects. First, the emotions of discomfort and anger resulting from humiliation, 
abiertas por desmitificar los prejuicios injuriosos sobre el 'Sur' y por otro lado los sentimientos de retraimiento que en determinadas circunstancias conducen a la negación o encubrimiento del lugar de residencia para evitar la desacreditación social.

\section{PALABRAS CLAVE: EMOCIONES, QUITO, RECONOCIMIENTO, ESTIGMA TERRITORIAL, TOPOFILIA.}

Recibido: 01-03-2017.

Aceptado: 31-08-2017.

1 Este artículo es parte de la difusión de resultados del proyecto de investigación titulado "Segregación socio-espacial y experiencia urbana: una mirada desde las subjetividades", código FDA IP 745, desarrollado durante el año 2014 con el auspicio de FLACSO Ecuador.

2 Ecuador. Departamento de Antropología, Historia y Humanidades, FLACSO. Correo electrónico: asantillan@flacso.edu.ec. which gives rise to the emergence of disputes to demystify injurious prejudices towards the 'South'. Second, the feelings of withdrawal which, under certain circumstances, deny or disguise the place of residence to avoid social discredit.

KEYWORDS: EMOTIONS, QUITO, RECOGNITION, TERRITORIAL STIGMATIZATION, TOPOPHILIA.
Received: 01-03-2017.

Accepted: 31-08-2017.

1 This paper is part of the FDA IP 745 research project entitled "Socio-Spatial Segregation and Urban Experiences: An Overview from Subjectivity", developed during 2014 and funded by FLACSO-Ecuador.

2 Ecuador. Department of Anthropology, History and Humanities, FLACSO.Email: asantillan@flacso.edu.ec. 


\section{Introducción}

El reconocimiento de la importancia de la subjetividad para las ciencias sociales contemporáneas constituye uno de los campos más fructíferos e innovadores de investigación. Los estudios sobre cuerpo, emociones, sensibilidades, identidades, memorias, imaginarios y muchas otras expresiones subjetivas de la vida en común han renovado en buena medida las explicaciones clásicas de la dinámica social (Grosso y Boito, 2010; León y Zemelman, 2007). Sin embargo, la preocupación por las problemáticas que envuelven a la subjetividad en los estudios urbanos aún no ha tenido una acogida lo suficientemente amplia o, en el mejor de los casos, ha tenido una presencia marginal. Como bien señala Lindón, el pensamiento urbano históricamente conlleva un fuerte "sesgo materialista" cuya consecuencia ha sido la invisibilización de los elementos inmateriales del espacio, de las percepciones, significaciones y también de los componentes afectivos o emocionales. Esta perspectiva implica recuperar el protagonismo de los sujetos en las dinámicas urbanas, pensando que "no sería posible comprender el espacio vivido, percibido, imaginado, representado, experimentado sin empezar por quien lo vive, lo imagina, lo experimenta" (Lindón, 2012, p. 597).

Este abordaje ha sido bastante fructífero en la comprensión de la denominada "estigmatización territorial" (Wacquant, Slater, y Borges, 2014), como se conoce en el contexto angloparlante a la denigración sistemática de las poblaciones residentes en barrios que presentan marcadas condiciones de degradación física y simbólica. Estos trabajos, en buena medida inspirados en el argumento del "efecto de lugar" desarrollado por Bourdieu (1999) y en la reflexión de Goffman (2006) acerca de los efectos del estigma social en la identidad personal, proveen una lectura que entrecruza las estructuras objetivas expresadas en la morfología del espacio urbano, con los procesos subjetivos que atraviesan la construcción de significaciones sobre el lugar.

En el contexto latinoamericano también existen trabajos relevantes dedicados a recuperar testimonios que relatan la experiencia de "sentirse relegado", tomando en cuenta el crecimiento de las desigualdades como marca característica de las ciudades latinoamericanas (Carman, Cunha y Segura, 2013; Cornejo, 2012). Un elemento a destacar de estos trabajos es que presentan importantes matices respecto a la matriz bourdiana en cuanto a la conceptualización de la estigmatización territorial, sobre todo en lo referido a cierta "pasividad" de los residentes frente a la reivindicación de sus espacios de residencia. En ciudades fuertemente caracterizadas por la autoproducción del hábitat, con los consiguientes repertorios de ocupación, construcción y muchas veces de auto-abastecimiento de servicios, el vínculo con el espacio está 
atravesado por la puesta en marcha de diversas formas de agencia colectiva que lo construyen material y simbólicamente (Bolívar y Erazo, 2013).

En este marco de discusión, este artículo presenta algunos resultados de investigación respecto a la experiencia de segregación residencial en la ciudad de Quito. A partir del análisis del "acto de habla" sobre relatos de estigmatización territorial, se busca identificar y comprender las emociones que están en juego en la construcción del sentido de habitar espacios estigmatizados.

\section{Quito: de la segregación física a la segregación imaginaria}

Aunque el concepto de "imaginario urbano" es una herramienta teórica en desarrollo, una de las principales confluencias entre quienes lo han acuñado para la investigación sobre la vida urbana es su distancia de las acepciones comunes del término asociado a lo irreal, a lo falso o a la carencia de fundamento empírico de una creencia. Desde la concepción de Silva, por ejemplo, fenómenos sociales como la percepción y la representación son constitutivos de la construcción de realidad, y en su génesis está presente una profunda proyección de deseos y fantasías que se materializan en las formas de habitar la urbe. Por esto, como dice el autor, el imaginario se vuelve "más real que lo real" (Silva, 2013, p. 186).

Este recurso conceptual sirve para sintetizar el proceso que ha seguido la dialéctica entre el orden material y simbólico de la capital ecuatoriana. Desde las primeras décadas del siglo XX, la división de clases en la ciudad se "espacializó", las élites se desplazaron desde el antiguo centro colonial (conocido ahora como centro histórico) hacia el norte geográfico, mientras que las clases medias ocuparon dicho centro y las nuevas clases populares se asentaron en la zona sur. Este orden socio-espacial se ha modificado sustancialmente durante la segunda mitad del siglo XX. Sin embargo, se mantiene vigente una representación dual de la ciudad en la cual los términos 'Norte' y 'Sur' adquieren connotaciones sociales que sobrepasan su sentido geográfico, por lo cual se puede hablar de un 'Norte' y 'Sur' figurativos que funcionan como opuestos: el primero asociado a los privilegios sociales y el segundo a una posición desfavorecida (Santillán, 2015a).

En el orden material, el proceso de conformación de la zona sur condensa, entre las décadas del cincuenta y el ochenta, la combinación tanto de la segregación planificada (acciones) como de la desregulación y la falta de aplicación de las normativas de la acción pública (omisiones). En este momento 
el paisaje urbano puede asociarse en gran medida al modelo prototipo de asentamientos precarios latinoamericanos en los cuales "la instalación del habitante precede al marco urbanizado cuyo acondicionamiento requiere varios años" (Deler, 2014, p. 125). A partir de los años noventa, la zona sur alcanza aproximadamente el 40\% del área de la ciudad y cerca del $50 \%$ de la población con un proceso importante de consolidación urbana, especialmente en la última década. Sin embargo, en el plano simbólico mantiene hasta la actualidad una imagen peyorativa asentada ahora más en la representación como un espacio relegado antes que en carencias materiales objetivamente medibles. Si bien la distribución isotrópica de servicios e infraestructura en el territorio aún mantiene importantes desfases, es claro que la representación se ha liberado de su anclaje en lo material y ha cobrado vida propia. En la medida en que ya no requiere de la precariedad espacial para persistir, su soporte está en el imaginario como trasfondo que "hace representar" el territorio de una forma dual, en lugar de otras formas de representación posibles.

Este desfase entre el orden material y el orden simbólico de la ciudad puede sintetizarse de la siguiente manera: para el urbanismo, la ciudad tiene una estructura centro-periferia en la que las zonas
Centro, Centro Norte y Centro Sur constituyen una "macro-centralidad" con buenos niveles de cobertura de servicios y se encuentran rodeadas, tanto hacia el norte como hacia el sur, por áreas periféricas aún en proceso de consolidación. Sin embargo, para la población, la frontera histórica norte-sur se mantiene vigente y es usada como referente de pertenencia socio-económica (Santillán, 2015b).

Los trabajos de Carrión (1987 y 2012) muestran la capacidad de las élites para definir la morfología de la ciudad, pero habría que añadir su rol preponderante en definir también su representación. La investigación muestra la existencia de una visión "norte-céntrica" que ha logrado imponer una delimitación arbitraria que demarca una parte de la ciudad y su población como espacio legítimo, el llamado 'Norte', frente a la cual una variedad de territorios contiguos han sido pensados como lugares cuya integración a la ciudad se pone en duda. La expresión más notoria de esta ideología es la idea de que "el 'Norte' es Quito", refiriéndose exclusivamente al Centro Norte y dejando por fuera tanto al Norte Periférico como al Sur Central y al Sur Periférico.

La figura 1 esquematiza el orden simbólico norte-céntrico y añade los flujos de descalificación generales: 
Figura 1. Orden Norte-Céntrico y flujos de DESCALIFICACIÓN.

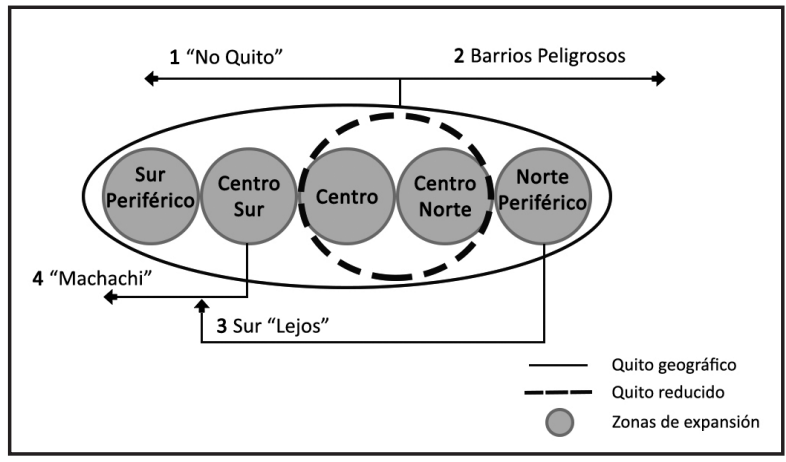

Fuente: Elaboración del autor.

1. Desde el Quito reducido se define a las distintas áreas del Sur como "otra ciudad" o "no Quito".

2. También desde esta ubicación se descalifica al Norte Periférico a partir de la noción de "barrios peligrosos".

3. Desde el Norte Periférico se descalifica indistintamente a las zonas del Sur como una parte lejana de la ciudad.

4. Un recurso similar es utilizado al interior de la zona Sur, ya que desde la zona Centro Sur se utiliza la expresión "eso ya es Machachi"3 para referirse al Sur Periférico.

Varios trabajos han destacado la importancia de la dimensión simbólica de la imagen negativa del sur de Quito (Aguirre, Carrión y Kingman, 2005; Naranjo, 1999), pero lo que no se ha explorado son los efectos de cómo las cualidades negativas asignadas al espacio se trasladan a las personas, asumiendo que su carácter ficcional las hace inocuas. Como se verá más adelante, este supuesto resulta erróneo a luz de la información proporcionada por el análisis de las emociones expresadas en los relatos.

Finalmente es importante mencionar que el "derecho de pertenencia" a Quito ha sido históricamente un conflicto socio-espacial, en tanto ciertas áreas de expansión y las poblaciones de reciente incorporación a la ciudad han sido permanentemente deslegitimadas (Kingman, 2006 y 1992). Así, la particularidad que presenta Quito en comparación a la literatura sobre estigmas territoriales es que uno de los estigmas más eficaces de la ciudad recae no sobre unos barrios específicos que concentran poblaciones consideradas "minorías", sino que se vierte sobre una extensa zona altamente heterogénea y que concentra la mayor densidad poblacional.

3 Machachi es un poblado ubicado fuera del límite del Distrito Metropolitano de Quito. Su utilización como referencia es una manera de remarcar la no pertenencia a la ciudad. 


\section{Topofilia y disputas de reconocimiento. Una propuesta conceptual para repensar los estigmas territoriales}

La obra de Yi-Fu Tuan es considerada primordial en el desarrollo de la Geografía Humana a partir de la introducción del concepto de 'lugar' como categoría que incluye a los sujetos en la construcción de la espacialidad (Lindón, 2012 y Peña, 2011). Sin embargo, no se ha reflexionado lo suficiente sobre la importancia que le da el autor a las emociones como soporte de esta categoría, ya que el vínculo que transforma al espacio en lugar se resume en la noción de 'topofilia', que contempla percepciones, actitudes y valores frente al 'topos' en que se asienta la vida humana. La definición de topofilia dice que ella corresponde al "lazo afectivo entre las personas y el lugar o el ambiente circundante. Difuso como concepto, vívido y concreto en cuanto experiencia personal" (Tuan, 2007, p. 13).

La gama de sentimientos topofílicos que analiza el autor es vasta, desde la admiración estética del paisaje que se observa por primera vez, hasta el amor al suelo natal, sin desconocer además la gran variedad de mediaciones culturales que existe en la relación de las distintas sociedades con su medio físico. Esto implica que los seres humanos no solamente ocupan un espacio, sino que lo habitan, esto es, lo dotan de significaciones insertándolo en un orden simbólico. Así la relación humana con el espacio es capaz de invertir en él emociones profundas a través de los fenómenos de arraigo y apego como expresiones máximas de la vinculación emocional con el lugar. Entonces cabe preguntarse ¿cómo se experimentan los sentimientos topofílicos en contextos marcados por la desvaloración de la persona por su lugar de residencia?

La producción teórica y empírica de Wacquant da valiosos elementos sobre las estrategias que adoptan los sujetos para enfrentar la estigmatización territorial, figurando entre los más destacados "la no revelación de sus direcciones, abstenerse de invitar a terceros a sus hogares, refugiarse dentro del núcleo familiar, restringir su participación en grupos locales y migrar de su lugar de residencia ante la primera oportunidad que se presente" (Wacquant et al., 2014, p. 223). Algunas de estas estrategias, conscientes o inconscientes, también han sido reportadas en trabajos latinoamericanos (Sabatini, 2006), pero es importante destacar los trabajos que documentan estrategias de revalorización del lugar habitado, a través de "dignificar" el barrio frecuentemente desde intervenciones estéticas (Bolívar, Erazo y Rodríguez, 2015; Carman et al., 2013). Estas compilaciones muestran en general que la activación del tejido social no solo construye el hábitat en términos físicos, sino que para los habitantes el tema del reconocimiento es también valioso. 
Para profundizar teóricamente en el reconocimiento social como un campo profundo de disputas sociales son relevantes los aportes de Honneth. Su pensamiento contribuye a replantear la idea de justicia social, que durante el siglo XX ha girado principalmente en torno a la redistribución equitativa de bienes como fundamento de equidad. En sus palabras:

Desde hace algún tiempo, el lugar de esta influyente idea de justicia, que desde el punto de vista político puede entenderse como la era socialdemócrata, parece ocuparlo una nueva visión que, en un principio, resulta políticamente mucho menos clara: el objetivo normativo parece no ser ya la eliminación de la desigualdad, sino la prevención de la humillación o del menosprecio; las categorías centrales de esta nueva visión ya no son la distribución equitativa o la igualdad de bienes, sino la dignidad y el respeto (Honneth, 2010, p. 10).

Basado en la triada de instituciones que moldean lo social planteada por Hegel, la familia, el Estado y la sociedad civil, Honneth plantea una taxonomía de las formas de reconocimiento social que conllevan a una relación positiva del individuo consigo mismo, pero construye este modelo utilizando la argumentación negativa para identificar primeramente las formas de menosprecio y las afectaciones o daño moral que ocasionan en el sujeto la falencia en la asignación de reconocimiento. El plano que resulta relevante para este análisis es el espacio de la sociedad civil en el cual el menosprecio se ejerce a través de la desvalorización social del individuo o grupo y que se traduce como "indignidad-injuria”. La forma de reconocimiento correspondiente es la "solidaridad", en la cual se valoran las diferentes capacidades individuales y formas de vida en general, produciendo en el sujeto una relación de autoestima consigo mismo.

Wacquant propone la noción de "topografía del desprestigio" en el estudio de los estigmas territoriales, remarcando la labor institucionalizada de actores como los funcionarios institucionales, medios de comunicación y en parte la misma academia en su reproducción (Wacquant, 2011; Wacquant et al., 2014). Aunque esta noción se puede apreciar en el material de campo analizado, la característica más notoria identificada en los testimonios es que el menosprecio se ejerce en la vida cotidiana en una relación intersubjetiva, es decir que proviene desde otros sujetos que asumen una posición de superioridad asociada a lo 'Norte'. En este sentido la disputa por la construcción de un sentido topofílico se juega en la relación con los otros, antes que frente a instancias institucionales, por lo que resulta pertinente no solo describir una "topografía del desprestigio" sino analizar, en este caso, la "performática del desprestigio". 


\section{Trabajar sobre las narrativas. 'Relatos de espacio' como actos de habla}

Michel de Certeau (1996, p. 130) propone que la noción de "relato de espacio", para referirse a la manera en que se describe un lugar, hace explícita una forma de aprehenderlo y experimentarlo, considerando la capacidad del mismo para superponerse sobre la materialidad, pues los relatos trazan itinerarios que enlazan lo que no necesariamente está físicamente conectado y a la vez identifican límites que pueden carecer de barreras propiamente físicas. Así, lo que se dice del lugar lo hace existir de una manera particular, descartando otras posibles significaciones.

Esta propuesta requiere, en el plano metodológico, una visión amplia del lenguaje, partiendo de que el significado de lo expresado no es transparente, ni una construcción únicamente personal, sino que existen capas de significación interactuantes y que a través del sujeto se expresa el discurso social como sentido común internalizado. En este sentido, no basta con "dejar hablar" a los informantes para que expresen su verdad, sino asumir que la narrativa es selectiva pues reordena la experiencia en un escenario de interacción social, en la que la alocución no puede ser comprendida sin examinar las condiciones sociales que regulan el decir (Blum-Kulka, 2005; Escalante, 2009; Follari, 2011)

Arfuch sostiene que trabajar la narrativa implica tomarse en serio el lenguaje:

no ya como una materia inerte donde el investigador buscaría aquellos "contenidos", afines a su hipótesis o a su propio interés, para subrayar, entrecomillar, citar, glosar, cuantificar, engrillar... sino, por el contrario, como un acontecimiento de palabra que convoca una complejidad dialógica y existencial (Arfuch, 2002, p. 190).

Los relatos analizados provienen de una selección de dos grupos focales con una composición diversa en edad, género y condición socio-económica, aplicada a residentes del sur de Quito. La conversación de los grupos focales giró en torno a dos preguntas: 1) ¿Qué se dice sobre el sur?, en la que se utilizó a los informantes como cronistas de las expresiones frecuentes para referirse a esta zona, y 2) ¿Qué opinión les merecían tales expresiones?, como pregunta para captar el posicionamiento del informante respecto al campo del "decir sobre el sur". El análisis recurrió a los procedimientos sugeridos por la pragmática lingüística, en donde cobra importancia el acto de habla en su totalidad como constructo en donde el nivel léxico-semántico de "lo dicho" adquiere sentido únicamente en relación a una multiplicidad de elementos 
comunicativos del "cómo se dice" (Arfuch, 2002; Blum-Kulka, 2005).

De todo el material analizado, para este artículo se han seleccionado los momentos de clímax en la conversación que produjeron alocuciones altamente emotivas. Si bien hasta cierto punto los informantes mostraron experticia en controlar el discurso en función de lo que consideran oportuno decir, en los momentos más efusivos, los elementos no verbales de la comunicación se desbordaron a través del cuerpo y la gestualidad. Así, la entonación y el ritmo son analizados como recursos comunicativos, pero además son profundamente elocuentes las pausas, los silencios, las interjecciones, etc.

Los elementos verbales y no verbales que remiten a las emociones en juego, se presentan con cursivas añadidas para resaltar su importancia. Para la presentación de la información, los nombres de los entrevistados han sido cambiados como una manera de proteger su identidad pese a su consentimiento de participar en la investigación.

\section{Las ambivalencias de la topofilia en el 'Sur' de Quito}

\section{REIVINDICACIONES FRENTE AL HUMOR QUE MENOSPRECIA}

\section{Grupo focal 1: ¿Qué Se dice sobre el sur?}

Carmen (25 años, propietaria de un negocio): [Sonríe] Bueno, aspectos que generalmente la gente dice, no son los de acá [se refiere a los habitantes del sur]. Primero nos dicen que somos pooobres [cambia la entonación, como teatralizando, se sonríe], de lo peor (...) que somos pobres, nos dicen que el sur es feo, (...) que es lleno de basura, te respetan menos, que no sé qué, que no sé cuánto. (...) [hace pausa, suspira levemente y sonríe] eso dicen en general de mi pobre sur [suspira, risas de todos], que somos pobres, que no tienen plata... y verán, nosotros no vendemos con tarjeta de crédito, nosotros vendemos acá solo en efectivo [cambia el tono, seria y tajante], entonces lo que nosotros optamos es que aquí nos compran en efectivo [cierra el puño y golpea suavemente la mesa] y sí tienen (en referencia al dinero) [luego se ríe y Felipe asiente con la cabeza]. 
Felipe (22 años, estudiante, practica hip-hop): Ya que solo han dicho cosas malas, voy a comenzar por algo bueno que he escuchado [risas de Carmen], yo he escuchado que muy comúnmente dicen "en el sur la vida es más sabrosa" [risas de Carmen], entonces eso es lo que en general se habla con los panas ${ }^{4}$. Yo supongo para mí que en el sur la vida es más sabrosa porque en realidad [pausa larga] se, se distancia mucho del norte porque aquí la gente es más cálida, más atenta, es más simpática [pausa, duda de lo que quiere decir]. No sé yo [demora lo que quiere decir], a veces en el norte me cohíbo, es como que siento algo extraño que me hace sentir incómodo, así [mira al facilitador], acá es más abierto [levanta sus brazos, y los abre y sonríe], es más así como que [pausa, sonríe] ¡el desmadre! [sube el volumen, levanta los brazos animosamente y Carmen se ríe], también a veces [sigue con los brazos levantados y hace unos sonidos con la boca como de fiesta, moviendo los brazos al ritmo de esos sonidos], no sé, en el sur la vida es más sabrosa. De ahí también he escuchado algunas cosas referentes a... a... [pausa], por ejemplo puse que he escuchado, que saben decir: "el sur es como otra ciudad"

4 Amigos. y no [pausa] una muy segura, o sea la diferencian, la distancian con una barrera [hace la mímica de barrera-muro con la mano], haciendo pensar de que [pausa] ya no es Quito, es otro, es otra parte, o sea Quito llega solo hasta el centro, o hasta el norte. El norte es Quito [mueve las manos enfatizando, sube el volumen y su tono es tajante. Los demás participantes se ríen y mueven la cabeza en señal de desaprobación a la idea de que "el norte es Quito"] para algunas personas el sur es otra ciudad. Entonces, yo he escuchado que dicen: "hasta el Panecillo y su Virgen les dan la espalda" [Carmen exclama: "¡ah, sí!", señalando que ha escuchado esol $]^{5}$.

Este extracto de la discusión condensa el muestrario de emociones que se producen al hablar sobre la imagen ambivalente del 'Sur'. La alocución de Carmen se construye con una serie de recursos performáticos como la entonación y la teatralización que dejan ver su malestar frente a la imagen despectiva del 'Sur'. Señala la asociación permanente con la pobreza y la valoración de esto como "lo peor", luego remite a la estética con el calificativo de 'feo' aludiendo a la presencia de basura en los parques, ante lo cual expresa que por estas asociaciones "te

5 La Virgen del Panecillo es una estatua de carácter religioso ubicada en el cerro llamado Panecillo, en el límite sur del centro histórico. Desde los años setenta existe la fabulación de que su ubicación de frente hacia el centro y el norte conlleva explícitamente la intención de ignorar al sur, que mira únicamente su espalda. 
respetan menos", y refiere figuradamente más expresiones en este tono diciendo "que no sé qué, qué no sé cuánto", que prefiere no explicitar. A partir de este cúmulo de referencias negativas hace una pausa larga, suspira y con desaliento afirma que "eso dicen de mi pobre sur", lo que genera varias risas en los demás interlocutores. Esta última frase muestra la tensión de identificación topofílica en contextos de estigmatización, pues a través del pronombre posesivo 'mi' se manifiesta el sentido de apego y pertenencia al lugar, pero a su vez el adjetivo 'pobre' refiere un sentimiento de compasión frente al desprestigio sistemático. Después, al contar que su clientela del sur paga únicamente en efectivo, la firmeza en la entonación y el gesto de golpear la mesa demuestran un sentido de afirmación frente a la injuria que adquiere un sentido reivindicativo.

Por su parte, la alocución de Felipe aporta no solo contenidos significativos, sino que también a partir de recursos histriónicos revela la identificación afectiva con el espacio. Al hacer explícita su intención de ponderar las "cosas buenas del sur" elabora una comparación con el 'Norte' en cuyo ambiente afirma "sentirse cohibido", mientras que en el 'Sur' siente que puede expresarse espontáneamente. Así, su narrativa ubica nuevas coordenadas de comparación en las cuales sugiere una serie de virtudes del ambiente del 'Sur' muy emocionales como la 'alegría' y 'calidez'. Sin embargo, en su misma intervención aparece la contracara de la referencia al 'Sur' como lugar marginado, añadiendo un testimonio muy valioso referente a la broma de que "Quito llega solo hasta el Centro" y por ende el 'Sur' queda relegado simbólicamente de la pertenencia a la capital. Al tocar este tema decaen la espontaneidad y los recursos performáticos que caracterizaron su relato reivindicativo, y pasa a contar la experiencia de segregación en un tono más serio.

\section{Grupo Focal 2: ¿Qué Se dice sobre el sur?}

Alicia (45 años, trabaja en la limpieza de un hotel): (...) se escucha [pausa] yo por ejemplo trabajo en un hotel y siempre se escucha ehhh [pausa], uno se dice "¿dónde vives?", "en el sur", "uuuyyy [tono de crítica], cómo vas a vivir ahí en ese frío, lejos, por ahí no hay nadie, ahí no existe Dios" [risas de varios] y yo "ipero cómo que no existe Dios?, si somos más alegres que en el norte". Entooonces... [pausa] a mí [pausa, se toca el pecho] me afectó bastante. Vino una proveedora y dice "voy a poner una sucursal en el sur" y otra señora le dice "iy por qué?" y dice "cómo va ir, si ahí solo vive chusma, ¿quién te va a hacer el gasto ahí?" [gestos de desacuerdo de quienes escuchan], entonces yo [pausa], o sea para mi era una ofensa [se toca nuevamente el pecho] y entonces yo le salí diciendo a la señora "icómo que la chusma!, si ustedes viven por la chusma" 
[tono furioso, se rien varios], "ustedes viven por la chusma, en el sur hay más dinero que acá y si es que en el sur hay chusma a qué se va a meter usted ahí". Entonces la gente [pausa], o sea la señora se quedó loca ${ }^{6}$. "Usted no tiene que ofender a la gente" [pausa] entonceees... que todos somos iguales, como dicen tenemos, o sea, damos el mismo servicio a ellos, entonces era una cosa ofensiva que la gente se exprese de aquí del sur.

Esteban (47 años, abogado, empleado municipal): Inclusive se relaciona hasta como medio chistoso... se enamoraba a una chica y todo bien hasta cuando dice "idónde vives?" y le dicen "en Chillogallo" [barrio del sur] "iUy!, ¿dónde es eso?" [risas estruendosas de varios]. Parecía lejísimo antes, ahora ya no.

Ketty (30 años, contadora en empresa privada): Todavía pasa eso (...) Muchas veces viven en Solanda (barrio del sur central) y les preguntan "idónde vives?", y por decir, dicen en Guamaní (barrio del extremo sur) y dicen "pero si eso está lejísimo".

Alicia: O sea, yo como trabajo de tarde, entonces el recorrido [del bus de la empresa] casi no me quería saber ir a dejar donde que yo vivo, usted sabe que la Biloxi [barrio del sur] es [pausa] cerca. Entonces ya empieza y dice "Uuuu, tú vives en el monte, sacas la mano y coges los conejos, la ola sube con sed, allá qué van a robar si los ladrones suben ya bien cansados" [risas]. O sea, siempre nos... da un poco de ira...

Este extracto del diálogo permite varios análisis. La intervención de Alicia constituye el punto de quiebre en la conversación con un testimonio de menosprecio que genera identificación en el resto de interlocutores y a partir de esto se toca un tema sensible, lo que abre un espacio para más relatos similares. La alocución, a manera de diálogos, recrea dos experiencias en las que se descalifica frontalmente al 'Sur'. La primera parte con la pregunta "idónde vives?", que se vuelve una pregunta interpelante porque implica develar una posición social. Tras la respuesta "en el sur" -nótese que no refiere ningún barrio en particular-, su interlocutor responde con una caracterización del lugar que utiliza el humor para la deslegitimación a través de la exageración ("uy, cómo vas a vivir ahí en ese frío, lejos, por ahí no hay nadie, ahí no existe Dios"), lo que genera risotadas del resto del grupo. Enseguida su relato refiere un incidente de ultraje más directo, donde se narra el cuestionamiento a colocar un negocio en el sur debido a que está habitado por "la chusma". Cabe resaltar en el 
relato la expresividad del lenguaje corporal, ya que Alicia tiende a tocarse el pecho mientras habla indicando explícitamente en el cuerpo el golpe a la autoestima y a esto le sigue su reacción de increpar a la persona agraviante, demostrando sentimientos de indignación y enojo, lo que es corroborado por quienes escuchan a través del lenguaje corporal.

A partir de aquí la conversación grupal adquiere un componente emocional muy fuerte, pues se crea un ambiente en el que está permitido mencionar las múltiples ofensas relativas a "ser del Sur", en buena medida gracias al humor que impregna el relato. Esto supone romper las barreras psicosociales que impiden comúnmente hacer públicas las experiencias de agravio. Esteban es el primero en reaccionar verbalmente a la experiencia de Alicia, ratificándola con otra experiencia. Cuenta que en el pasado, en el caso de "enamorar a una chica", iba bien hasta que nuevamente la pregunta "¿dónde vives?" reveló la identidad social y rompió el encanto del cortejo al presentarse como residente del sur. Al responder situándose en un lugar significado como "lejos" aparece nuevamente la exclamación "uuyy", que refleja una forma de rechazo, acompañada de la pregunta "¿dónde es eso?". Al escuchar esto, Ketty interviene para aseverar que no es solo una experiencia del pasado, sino situaciones aún comunes.
Alicia reanuda su testimonio y narra otro episodio nuevamente cargado de humor por la exageración y ficción. En este caso el transportista encargado de llevarla a su domicilio lo hace con cierto pesar y se refiere humorísticamente al barrio como situado "en el monte", que adquiere un primer sentido de ruralidad o naturaleza pura, al punto que "sacas la mano y coges los conejos", animales en estado silvestre; esto da pie ya no solo a la exageración sino al absurdo en tanto "el monte" en segunda instancia aparece relacionado con la altitud y se vuelve inaccesible a tal punto que "la ola sube con sed", y hasta evita la delincuencia porque "allá qué van a robar, si los ladrones suben ya bien cansados". El relato termina haciendo explícito el sentimiento de ira que produce la constante descalificación del 'Sur'.

La risa y muchas veces las carcajadas son elementos constantes en los relatos que surgieron a propósito de la pregunta "¿Qué se dice sobre el sur?" Sin embargo, el contenido expresado remite a situaciones directas o indirectas de humillación y deshonra. En los casos de ultraje más directo, aunque la alocución evoca emociones de ira e impotencia, las reacciones de los que escuchan crean un ambiente de hilaridad en tanto se reconocen y proyectan en la situación narrada. Esta empatía construye una suerte de "comunidad de agraviados" que a través de la risa se permite desaprobar las prácticas de 
menosprecio, ponderando las virtudes del 'Sur' y su gente y también cuestionando el lugar de enunciación desde donde se ejerce la práctica injuriosa.

En los casos en que el menosprecio se manifiesta desde el humor, a través de las exageraciones y los absurdos, se teje una dinámica distinta. Si bien estos recursos humorísticos atenúan la violencia directa del insulto, hacen posible el agravio sin que los destinatarios puedan enfrentarlo directamente ya que aparecen como una simple broma. Es el caso paradigmático de situar al 'Sur' como un lugar que queda "lejos". La distancia como construcción social solo es posible tomando un punto de referencia y este punto aparece en los relatos bajo la idea de que "el norte es Quito", refiriéndose a la construcción de un límite arbitrario que resulta contrario a la realidad de la ciudad. Este límite implica un proceso intencional de reducir la ciudad, pues no se niega la existencia del 'Sur' sino que no forma parte de la ciudad legible y reconocida. Es desde este sentido figurado que son posibles las múltiples fabulaciones, las exageraciones y los absurdos, que revisten de humor una ficción como expresión simbólica de un imaginario segregador. El sentido de menosprecio que conlleva este orden simbólico es justamente lo que convierte al sur geográfico en sur figurativo.

Los relatos obtenidos muestran que esta manera hegemónica de significar el lugar no es inocua en la vida de los residentes del sur, sino que genera sentimientos de malestar e indignación por el desprestigio considerado contra-fáctico. Sin embargo, el orden simbólico aviva la segregación que se encarna en rituales cotidianos de interacción, en donde el agravio provoca reivindicaciones impulsadas por sentimientos topofílicos. La identificación con el lugar permite a los sujetos confrontar y reclamar contra los comentarios "norte-céntricos", es decir, es posible la topofilia pese a los estigmas territoriales, pero requiere un sobreesfuerzo que en este caso pasa por crear un contra-estereotipo afirmativo en el que el 'Sur' pase a ser ahora un lugar depositario de las virtudes de lo popular, tales como la solidaridad, la vecindad, la alegría, la espontaneidad, etc.

\section{Negar el lugar. Localización y vergüenza}

\section{Grupo focal 2: ¿Qué opinan sobre lo oue se dice del SUR?}

Ketty (30 años, contadora en una empresa privada): Yo, yo pienso ehh que todos reaccionamos de alguna manera al momento de que "¡Ah!, tú vives en el sur, que ahí es frío, que hay bastantes delincuentes", ese tipo de cosas creo que reaccionamos mala... de mala manera 
[esto último lo dice más firme] con la gente, les decimos "qué te pasa si [pausa] el sur es [pausa] más sociable, hay más cosas", o como ese tipo de cosas, tratamos de responder con lo positivo que hay en el sur. Sin embargo, yo recuerdo que [pausa, se ríe, habla sumamente rápido] cuando yo estaba en la universidad, tenía compañeros de hecho que viven en el norte y sabían decir cosas como lo de [pausa] la película ${ }^{7}$ que "hasta la virgen les da las espaldas", entonces muchas veces [se ríe] cuando uno está entre amigos a uno se le salen groserías [se ríe de nuevo], y sabíamos decir "bueno, nos dará las espaldas, pero nos tocó la mejor parte" [se refiere a las nalgas], cosas así. O sea, uno ya la reacción sale como hasta grosería muchas veces porque tratan de minimizar a la gente que vive en el sur, hacerla de menos, como queeee [pausa] o... [pausa] somos poca cosa o queeee [pausa] tenemoooos no sé [pausa], una situación económica baja oooo [pausa] queeee somos delincuentes, que somoooos [gente] estafadora, deshonesta. Creo que en lo personal a mí me molesta porque realmente no es así.

Rolando: (32 años, tecnólogo médico, trabaja en el sistema público de salud): (...) yo lo que les sé contar a mis compañeros de trabajo

7 Se refiere a la película "A tus espaldas", de Tito Jara, centrada en las diferencias sociales de Quito. cuando me dicen algo así "itu dónde vives, Rolandito?", entonces yo les digo "en la Mena 2" [barrio del sur]. Entonces me dicen "uuuy hermano, la Mena 2" [teatraliza la voz como algo desagradable]. Entonces yo los cojo y les digo "a ver doctor, zusted conoce siquiera detrás de, de [pausa], de los Dos Puentes [barrio del centro que funciona como límite con el sur]?, ¿ha ido alguna vez por ahí? No" [cruza los brazos, dramatizando la conversación con algún companero de trabajo]. "Entonces usted es como las viejas chochas", le digo, "porque usted se deja [se toca la cabeza con el índice en señal de engaño] engañar del solo por que dirán y usted no ha comprobado por sus ojos" [entonación seria, indignado y ofendido] (...).

Paula (29 años, parvularia, trabaja en un centro infantil privado): Todo el mundo dice lo mismo, que la gente de acá es pobre, que la gente de acá es naca ${ }^{9}$, yo he tenido amigas y amigos cuando yo estudiaba: ique sí, que "tú vives en el sur", que eres... que los nacos viven allá, que la gente es pooobre... o sea la chusma" [hace una entonación despectiva y se ríe]. Así nos sabían decir a nosotros, entonces uno responde, como quien dice uno ya está a la defensiva [mueve las manos en señal de ataque, de saltar, como un

\footnotetext{
9 Término tomado del argot mexicano para referirse despectivamente a los sectores populares.
} 
gato cuando saca las uñas]. Entonces si alguno te dice algo, el otro comienza a... y comienzan así las discusiones también.

Laura (44 años, parvularia, trabaja en la educación preescolar): Sí, porque usted dice "sur" y "iay!" [como respuesta], ya lo ubican como si estuviera en el último escalafón [pausa] y no es así, o sea, yo no sé (...) el trato de nosotros hacia ellos [gente del norte] no es para tratar de ofenderlos, porque ellos en sí en la parte norte sí tratan de ofender a nosotros los del sur. $\mathrm{O}$ sea, porque al decir esto es una grosería y sin embargo como uno dice nos hemos tenido que defender sacando las cosas buenas, cosas positivas que tiene nuestro sur [enfatiza con entonación tajante], pero al decir "el sur" como que nos han dejado marcados y para salir de eso yo pienso queee [pausa] se debe hacer una campaña, qué sé yo, unos talleres para inculcar a las personas que el sur no es todo lo que ellos se imaginan ni todo lo que nos dicen a nosotros. Porque nosotros somos lo peor, la parte sur, en todos los sentidos.

Ketty: Yo creo que, estoy muy de acuerdo con lo dicho porque todo es ideología, de hecho ehh [pausa], nuestros jóvenes ehhh [pausa], los muchachos adolescentes que se están criando ahora y muchos que tienen ya mi edad, 27, 28, 29, 30 años, tienen una ideología [pausa, hace mueca] creo que [pausa] cerrada, colonialista; viven aquí en el sur y muchas veces les preguntan "idónde vives?" y tal vez vivan en la Lucha de los Pobres [barrio del sur], y por no decir que viven en La Lucha, dicen "vivo en Guajaló" [barrio del sur] porque se escucha menos feo. O por no decir que viven en Guamaní [barrio del sur], dicen vivo en Quitumbe [barrio del sur] o cosas así, o sea es la ideología [se señala la cabeza] que nosotros nos llevamos porqueee creo que nos han [pausa] menospreciado tanto que preferimos decir que no vivimos en un barrio que tiene un nombre supuestamente feo [hace comillas con las manos] (...).

Facilitador: ¿Y es muy común esto de negar el lugar donde se vive, acá en el sur? [todos responden "si" sin dudar o asienten con la cabeza].

Santiago (34 años, abogado, servidor público del sistema judicial): Yoooo [pausa], en el poco tiempo que vivo acá, he visto queee [pausa], que todavía como que sigue enraizado [entrelaza las manos] y arrastrado todavía ese pensamiento de hacendado [pausa] y campo, (...) Y es algo que si tú te pones a escuchar las personas que viven en el norte o que viven en el sur y que llegan a un estatus deee [pausa], de puesto [pausa], para que me respeten me tengo que ir a vivir en el norte [pausa], asiii no tenga qué comer. Pero ya viviendo en el norte me empiezan a respetar por mi estatus. Entonces es como que la misma gente no piensa la relación interna de yo vivo aquí 
y punto, ya. Pero es eso de que viene arrastrándose de anteriormente [mueve las manos como dando cuenta del tiempo] en Quito mismo, como que el quiteño que vive en el centro y del centro o [pausa] al norte [señala con el brazo en dirección norte] ya es una persona de clase alta, que tiene una ascendencia [énfasis, entonación teatralizada, pomposa, mueve la mano hacia arriba] colonial, una ascendencia republicana o conservadora y que los del sur son los empleados de ellos [Alicia, Laura y Ketty asienten con la cabeza]. Acáaa [pausa] cuando uno llega de provincia lo que dicen "idónde vas a vivir? al sur no" [niega con las manos]. "Tienes que vivir en el norte para que la gente te respete", o "para que tengas acceso a mejores cargos, a mejores puestos", entonces nosotros lo empezamos a hacer cosa de nosotros [pausa].

Este extracto corresponde a uno de los momentos álgidos del debate grupal. Las intervenciones son largas, con pocas pausas para pensar una posible respuesta adecuada, los relatos abundan en detalles de los diálogos recreados y en la dramatización de los mismos, y los contenidos discurren en varios temas, pero la constante es la afectación a la honra en función del lugar. Se utilizan directamente palabras como "menosprecio" y "discriminación", y se expresan sentimientos de indignación más con los gestos y movimientos que con el lenguaje verbal, que pese a todo se conduce en términos políticamente aceptables ya que no aparecen insultos o "malas palabras".

Sin embargo, un tema revelador de este fragmento, y que resulta de mayor importancia en cuanto efecto del menosprecio, es el ocultamiento del lugar de residencia en diversos contextos. El hecho de que una estrategia de presentación social, en un marco de situaciones muy diversas, implique mentir sobre el lugar de residencia da cuenta de la afectación a la autoestima que genera el descrédito por el lugar de residencia. La vergüenza es un sentimiento de naturaleza propiamente social, que opera en la visibilidad pública de no alcanzar un "deber ser" naturalizado. La alocución de Ketty aporta una gran cantidad de elementos acerca de cómo se falsea la localización como recurso para obtener una ganancia que no solo es simbólica, sino que puede también significar réditos materiales. Situarse en "Guajaló" en vez de "Lucha de los pobres", aunque son barrios cercanos, permite una ganancia al referir un nombre "menos feo" al quitarle las implicaciones históricas de un barrio que optó por incluir en el nombre su propio proceso de conformación. En el otro caso referido, situarse en "Quitumbe" en vez de "Guamaní" representa una ganancia locacional importante, ya que los separa una distancia considerable: Guamaní es un barrio del extremo sur, mientras Quitumbe constituye una centralidad urbana consolidada comercial y residencialmente. 
La pregunta "idónde vives?" pone sobre la mesa el orden simbólico de la ciudad reducida, a la cual se asume como deseable pertenecer de acuerdo al imaginario hegemónico. En este campo, para quienes no viven en este sector la pregunta en varios contextos se vuelve incómoda. Las estrategias y formas de encubrimiento son prácticas que en última instancia apuestan por la negación del lugar, de manera análoga a lo reportado en la literatura sobre la manera en que operan los estigmas territoriales en las metrópolis postindustriales. Pero en el caso de Quito, como ejemplo de las dinámicas de las ciudades andinas, tanto la puesta en práctica del menosprecio como las formas de encubrimiento social evocan las antiguas dinámicas coloniales, como lo expresa el testimonio de Santiago.

La lectura común de la negación del lugar es que se trata de un conflicto individual de una persona "acomplejada" que no acepta su adscripción social y se deja llevar por la presión del "qué dirán", a tal punto que se ha convertido en una caricatura que incentiva aún más el menosprecio, pues ridiculiza la misma opción del encubrimiento. Esta interpretación frecuente sigue la lógica de la violencia simbólica (Bourdieu y Passeron, 2001), pues al responsabilizar exclusivamente a la persona que encubre queda naturalizada la estructuración de la clasificación social a través del lugar de residencia. Los relatos obtenidos son críticos respecto a la ideología norte-céntrica y señalan la importancia de la socialización de la desvalorización del 'Sur' como algo que trasciende lo individual, manteniendo en este sentido cierta distancia con la interpretación común de la negación. Sin embargo, no logran escapar del todo a la violencia simbólica, en la medida en que el agravio sistemático no logra ser identificado como objetivo político. Un orden urbano en el cual es necesario falsear el lugar en el que se reside para volverse legible entre sus coordenadas de visibilidad, constituye una forma de exclusión tan concreta como la desigualdad en el acceso a los elementos materiales del bienestar.

\section{Conclusiones}

El estudio de la dimensión subjetiva de la marginalidad urbana se ha convertido en una temática que ha ganado terreno en la agenda de investigación de las ciudades actuales. Si bien se han documentado los marcos de percepción hegemónicos que constituyen los estigmas territoriales y las acciones y reacciones que se desprenden de dichos esquemas de percepción y representación, las emociones no han sido tomadas como una arena central en la problematización de las tensiones, que representan para el vínculo afirmativo con el espacio las distintas formas de estigmatización territorial. En este contexto, el artículo propone incorporar a las investigaciones sobre segregación el estudio de la topofilia, las emociones y los afectos a través de los 
cuales se construyen las relaciones entre sujetos y lugares.

El estudio de las narrativas de personas residentes en el sur de Quito, una zona que puede considerarse estigmatizada no tanto por presentar las carencias comunes que se establecen como variables de segregación como dotación de servicios básicos e infraestructuras urbanas, sino más bien por su mala reputación. Esta reputación deviene de un orden simbólico-imaginario, que recrea la imagen de zona relegada históricamente hasta la actualidad. Este caso particular aporta información empírica sobre la topofilia en contextos de segregación que se pueden sintetizar en dos frentes. Por un lado, las emociones de malestar e ira frente a la humillación, que se capitalizan en disputas abiertas por desmitificar los prejuicios injuriosos sobre el 'Sur', reivindicando una serie de atributos positivos, muchos de ellos también emocionales como ser un espacio "alegre, fiestero y fraterno", entre otros. Por otro lado están los sentimientos de retraimiento y vergüenza que en determinadas circunstancias conducen a la negación o encubrimiento del lugar de residencia para evitar la desacreditación social. Aunque esta contracara no implique necesariamente sentimientos topofóbicos, pone en evidencia la tensión que genera la dominación simbólica que impone el imaginario, ya que obliga a mentir sobre la localización como un recurso útil en determinadas circunstancias de presentación social.

\section{Referencias bibliográficas}

Aguirre, M., Carrión, F., y Kingman, E. (2005). Quito imaginado. Bogotá: Flacso. 220 p. ISBN 958-704-298-0.

Arfuch, L. (2002). El espacio biográfico. Dilemas de la subjetividad contemporánea. Buenos Aires: Fondo de Cultura Económica. 272 p.

Blum-Kulka, S. (2005). Pragmática del discurso. En Van Dijk, T. (Comp.), El discurso como interacción social. Estudios sobre el discurso II. Una introducción multidisciplinaria (pp. 67-99). Barcelona: Gedisa.

Bolívar, T., y Erazo, J. (Eds.). (2013). Los lugares del hábitat y la inclusión. Quito: FLACSO Ecuador, CLACSO, MIDUVI.

Bolívar, T., Erazo, J., y Rodríguez, M. (Coords.). (2015). Ciudades en construcción permanente. ¿Destino de casas para todos? (Vol. II). Quito: Abya-yala.

Bourdieu, P. (Dir.). (1999). La miseria del mundo. Buenos Aires: FCE.

Bourdieu, P., y Passeron, J. (2001). La reproducción. Elementos para una teoría del sistema de enseñanza. (Libro 1). 2 vol. Madrid: Popular. 256 p. ISBN 978-84-7884-221-6.

Carman, M., Cunha, N.V.d., y Segura, R. (Coords.). (2013). Segregación y diferencia en la ciudad. Quito: FLACSO Ecuador. 228 p.

Carrión, F. (1987). Quito, crisis y política urbana. Quito: El Conejo. 
Carrión, F. (2012). La forma urbana de Quito: una historia de centros y periferias. Bulletin de Ll'Institut d'Études Andines, 41(3), 503-522. https://doi. org/10.4000/bifea.361.

Certeau, M.d. (1996). La invención de lo cotidiano. 1 Artes de hacer. México DF: Universidad Iberoamericana.

Cornejo, C. (2012). Estigma territorial como forma de violencia barrial. El caso del sector El Castillo. Revista INVI, 27(76), 177-200. https://doi. org/10.4067/S0718-83582012000300006.

Deler, J.P. (2014). Ciudades Andinas: viejos y nuevos modelos. En: Kingman, E. (Ed.). Ciudades de los Andes: Visión histórica y contemporánea (pp. 351374). Lima: Institut Français d'Études Andines.

Escalante, E. (2009). Perspectivas en el análisis cualitativo. Theoría, 18(2): 55-67.

Follari, R. (2011). Algunos problemas en torno a la investigación cualitativa. En Aproximación al análisis de datos cualitativos: Aplicación en la práctica investigativa. Mendoza: Universidad de Aconcagua.

Goffman, E. (2006). Estigma. La identidad deteriorada. Buenos Aires: Amorrortu.

Grosso, J.L., y Boito, M.E. (Comp.). (2010). Cuerpos y emociones desde América Latina. Córdoba: CEACONYCET-Universidad Nacional de Catamarca. $231 \mathrm{p}$.

Honneth, A. (2010). Reconocimiento y menosprecio. Sobre la fundamentación normativa de una teoría social. Madrid: Katz. 85 p.
Kingman, E. (2006). La ciudad y los otros. Quito 18601940: higienismo, ornato y policía. Quito: FLACSO.

Kingman, E. (1992). Ciudades de los Andes: Homogeneización y diversidad. En E. Kingman (Ed.), Ciudades de los Andes (pp. 9-54). Institut Francais d'Études Andines. https://doi.org/10.4000/books. ifea.2241.

León, E., y Zemelman, H., (Coords.). (2007). Subjetividad: umbrales del pensamiento social. Barcelona: Anthropos. 174 p.

Lindón, A. (2012). La concurrencia de lo espacial y lo social. En: Leyva, G. y De La Garza Toledo, E. (Eds.), Tratado de metodología de las ciencias sociales: perspectivas actuales (pp. 585-622). México DF: Fondo de Cultura Económica.

Naranjo, M. (1999). Segregación espacial y espacio simbólico: un estudio de caso en Quito. En Kingman, E. y Salman, T., Antigua modernidad y memoria del presente: culturas urbanas e identidad (pp. 327-335). Quito, FLACSO Ecuador.

Peña, L. (2011). Algunos elementos metodológicos para pensar espacialmente en ciencias sociales. Bogotá: Universidad Externado de Colombia-CIDS. 154 p.

Sabatini, F. (2006). La segregación social del espacio en las ciudades de América Latina. BID. Recuperado de https://publications.iadb.org/handle/11319/5324.

Santillán, A. (2015a). Quito. Materialidad y ficción de una ciudad segregada. Un balance de la bibliografía disponible. Revista Cuestiones Urbanas, 3(1), 93-116. 
Santillán, A. (2015b). Imaginarios urbanos y segregación socioespacial. Un estudio de caso sobre Quito. Cuadernos de Vivienda y Urbanismo, 8(16), 246263. https://doi.org/10.11144/Javeriana.cvu8-16. iuss.

Silva, A. (2013). Imaginarios, el asombro social. Bogotá: Universidad Externado de Colombia. 255 p.

Tuan, Y. (2007) Topofilia. Un estudio de las percepciones, actitudes y valores sobre el entorno. Madrid: Melusina. $351 \mathrm{p}$.

Wacquant, L. (2011). Desolación urbana y denigración simbólica en el hiperguetto. Astrolabio, 6, 4-18.

Wacquant, L., Slater, T., y Borges, V. (2014). Estigmatización territorial en acción. Revista INVI, 29(82), 219-240. https://doi.org/10.4067/ S0718-83582014000300008. 